\title{
25 Research Suare \\ Modeling the Impacts of Climate Changes on the Distribution of Aloe vera Species in Ethiopia
}

\section{Abdulbasit Hussein ( $\nabla$ abdulbasithussein111@gmail.com )}

Haramaya University College of Agricultural and Environmental Sciences https://orcid.org/0000-00025067-0104

\section{Sintayehu Workeneh}

Haramaya University College of Agricultural and Environmental Sciences

\section{Research Article}

Keywords: Ethiopia, suitability, Aloe vera, Maxent, environmental variable, climate scenario

Posted Date: September 8th, 2021

DOI: https://doi.org/10.21203/rs.3.rs-809404/v1

License: (c) (1) This work is licensed under a Creative Commons Attribution 4.0 International License. Read Full License 


\section{Abstract}

Climate change is considered to be one of the most significant challenges to global biodiversity in the 21 st century and remains the greatest challenge to biodiversity conservation in the future. Consequently, understanding the effects of climate change on biodiversity can enhance conservation efforts. The use of niche modeling to predict changes in the suitable distribution of species under climate change scenarios is becoming a hot topic of biological conservation. Thus, this study investigated the impacts of climate changes on the distribution of Aloe vera species of concern in Ethiopia. Occurrence data were obtained from the Global Biodiversity Information Facility (GBIF; www.gbif.org/ (1 March 2021)) and specimen collection of the Ethiopian biodiversity institute. Maxent models were used to predict the potential suitable distribution of the Aloe vera species under different climate change scenarios in the present day (the 2020s) 2050s, and 2070s in Ethiopia. In the modeling process, the Akaike information criterion (AIC) was used to choose the best combination of feature type and regularization multiplier. Variables relating to temperature and precipitation were more important variables in predicting Aloe vera species distribution in the optimal model. The predicted suitable distribution areas of Aloe vera were different for the different periods under different climate change scenarios. The suitable distribution area is predicted to become more fragmented in the future. Results reveal the climate conditions suffer the distribution of Aloe vera in Ethiopia and the likely changes to its distribution pattern in the future and Aloe vera are under great threat of extinction from climate changes, providing a scientific basis for the sustainable management, protection, and restoration of the suitable habitat of this economically important vegetation in the context of changing climate condition. Therefore, increased forest protection to prevent further forest cover losses will be key for the Aloe vera species conservation.

\section{Introduction}

Climate change is one of the major threats to biodiversity (Keith et al., 2008; Heller and Zavaleta, 2009; Sintayehu 2018) and is anticipated to aggravate biodiversity losses in the future (Thomas et al., 2004). With the continued increase in atmospheric Carbon, climate change may surpass habitat destruction as the greatest global threat to biodiversity over the next few decades (Leadley et al., 2010). Temperatures have been increasing by $0.20^{\circ} \mathrm{C}$ per decade since the $1970 \mathrm{~s}$ and global average precipitation increased by $2 \%$ in the last 100 years (IPCC, 2007). Xx Thus, climate change has already started affecting biodiversity in various ways. Nevertheless, it is impossible to understand a clear image of the impacts of future climate change on biological diversity due to the variability of climate projections (Pereira et al., 2010). However, based on our current understanding of how climate has affected biodiversity in the past we can anticipate similar impacts in the future.

Species distribution modeling uses to conclude the environmental requirements for the existence of a species based on the environmental variables taken from the known distribution areas and then predicts their future distribution (Elith \& Leathwick, 2009; Guisan \& Zimmermann, 2000). Niche modeling has been widely used in ecology, biogeography, and conservation biology such as conservation of endangered species ((Araújo et al., 2011; Engler et al., 2004)), selection of natural reserves ((Araujo et al., 2005; Early 
et al., 2008)), and influences of climate change on species distribution (Beale \& Lennon, 2012; Meynecke, 2004). At present, many algorithms such as BIOCLIM, DOMAIN, GARP, ANN, and MaxEnt have been developed for modeling species distribution across geographic space, most of these algorithms are userfriendly but their performance varies greatly (Araujo et al., 2005). These species distribution model, established based on the statistical association between species distribution and environment variables, consider only the environmental factors that control species distribution and do not consider the association between species, species evolution, extreme interference events, or species diffusion processes (Guisan \& Zimmermann, 2000; Lawler et al., 2006). The current correlation between species and the environment (climate) does not necessarily guarantee that it can be used to predict future species distribution; however, niche modeling is still the most commonly used method for assessing the long-term effects of climate change on species distribution at the regional scale.

The Maxent model, which is based on the theory of maximum entropy, is an effective model of species distribution. MaxEnt requires presence-only data and it is comparatively less sensitive to the number of occurrence records required to develop accurate models. The model simulates the potential geographical distribution of a species using the information on its current (present-day) distribution as well as various environmental data(S. B. Phillips et al., 2006; S. J. Phillips \& Dudík, 2008). The maximum entropy model is easy and quick to run, has a minor sample demand, delivers stable operation results, and permits prediction results to be examined (Estes et al., 2013; S. B. Phillips et al., 2006); thus, it is favored by many researchers(Elith \& Leathwick, 2009). However, the model is often employed using the default parameters or those published previously without consideration of the details of the algorithm or input parameters, and all the environment variables that can be collected are included in the model indiscriminately. This not only increases the complexity and uptime of the model, but also severely limits its scope and accuracy. Earlier studies have revealed how diverse environmental variables and parameters used in niche models affect the results (Kriticos et al., 2013; Sheppard, 2013). Complex models show poor performance in identifying key environmental variables and in transferring habitat suitability to new environmental conditions (Warren et al., 2014; Warren \& Seifert, 2011). The selection of suitable environmental variables and model parameters is an important step that must be considered in the application of the Maxent model to eliminate overfitting which leading to a decline in species-transfer ability(Porfirio et al., 2014; Qiao et al., 2015).

Aloe Vera is a semitropical plant that originated in the dry warm climate of Africa. It has been assigned to the Aloaceae or a broadly circumscribed family Liliaceae (the lily family) and associated with other Lily families like onion, garlic, and turnip families (Eshun \& He, 2004). currently, the aloe Species is found global and become an important herbal plant for human daily lives (Sahu et al., 2013). This plant has been used as a medicine for both livestock and human and therapeutic properties without any clear understanding or scientific analysis of the basis for such properties. Today, the production of Aloe vera gel, medicinal and cosmetic derived from the leaf pulp of the plant for different uses, has become a big worldwide industry(Eshun \& He, 2004). 
Aloe vera species are classified as endangered and vulnerable due to their small geographic ranges and severely fragmented habitats. Besides, these species are under great threat from climate change which has been observed over the past decades. Understanding the ecology and factors that limit the distribution of Aloe vera species across geographic ranges is essential for the efforts of conservation of a given species. Nevertheless, threats on species do not operate in isolation rather in integration with other threats; hence an understanding of the combined effects of these threats is essential for recommending operative management actions (Klanderud and Birks, 2003). Indeed, single-threat perspectives are inadequate for conservation when ecosystems are threatened by multiple co-occurring threats (Brook et al., 2008; Ormerod Mantykapringle et al., 2012). However, most studies examining how climate change affects biodiversity (Parmesan, 2006). Investigations on the impacts of climate change on the distribution pattern of the endangered Aloe vera have not been conducted in Ethiopia. Therefore, the main aim of this study was to investigate the climate changes impacts on the distribution patterns of Aloe vera species in Ethiopia

\section{Methodology}

\subsection{Study area}

Ethiopia is a country in the Horn of Africa within 315-N and 3348E, bordered with Kenya to the south, Somalia to the south and east dimension, Djibouti to the east, Eritrea to the direction of north and Sudan to the northwest, and South Sudan to the west direction. The country covers about 1.14 million $\mathrm{km}^{2}$, which is characterized by high and rugged plateaus and the peripheral arid and semi-arid lowlands. The elevations of Ethiopia are $4620 \mathrm{~m}$ above sea level on Mount Ras Dashen and $126 \mathrm{~m}$ below sea level in the Danakil Depression (CSA, 2016).

Aloe species are common in all the floristic regions of Ethiopia, including the floristic regions of Afar, Arsi, Bale, Gamo Gofa, Gojam, Gonder, Harerge, Kefa, Shewa, Sidamo, Tigray, Wellega and Welo(Sebsebe, 2010). Accordingly, the majority of Aloe spp. found in Sidamo floristic region (with 14 species) followed by Harerge, Bale, Shewa, Tigray, and Welo floristic regions (with 10, 8, 8, 7, and 7 species respectively). Demissew et al. (2001), analyzed the distribution of Ethiopia's aloe in terms of vegetation types and showed that the endemic and almost endemic species predominantly occurred in two types of vegetation. These are (1) dry, evergreen mountain forest and (2) acacia commiphora forests and scrubland.

Aloes are available in a variety of vegetation types at various altitudes in Ethiopia. Most aloes (approx. $48 \%$ ) are found at altitudes of $1500-2500 \mathrm{~m}$ in the medium altitude range. Some Aloes (about $34 \%$ ) are found at altitudes of 500-1500 m in semi-arid climates while other species of Aloe (about 14\%) could be live between altitudes of 2500-3200 m in high altitude area. However, few Aloes (about 2\%) survive at elevation ranges above $3200 \mathrm{~m}$ in the alpine area whereas the other few Aloe species (about 2\%) may live at altitudes below $500 \mathrm{~m}$ in arid climate(Oda \& AnbessaErena, 2017). 


\subsection{Occurrence records for Aloe vera species}

Occurrence points used for this study were obtained from two sources: (1) records of specimen collection of the Ethiopian biodiversity institute; and (2) the Global Biodiversity Information Facility (GBIF; www.gbif.org/). The obtained species occurrence data were been entered into Microsoft Excel and saved in "CSV." format. All points were mapped using ArcGIS 10.8 for visual observation and check spatial accuracy. The occurrence records were projected on the study area map to ensure that they were within the targeted region. Duplicate records were removed while ensuring that within each $1 \mathrm{~km}^{2}$ pixel there was only one record of the same species (Polce et al., 2013). A total of 245 locations with Aloe vera occurrence were recorded using the Global Positioning System (GPS) and field surveys.

\subsection{Environmental variables and Change assessment}

Environmental variables for aloes species distribution modeling were extracted from the WorldClim version 2 (http://www.worldclim.com/version2) database. WorldClim database comprises various climatic variables that are generated by interpolation of global climatic data such as temperature and precipitation (Hijmans et al., 2005). All climatic variables had a spatial resolution of approximately $1 \mathrm{~km}^{2}$ (the 30s) and were downloaded from the WorldClim dataset (www.worldclim.org). To select the final set of environmental variables for each maxent model, an initial model with a full set of environmental variables was run and the least contributing variables based on percent contribution to the model and jackknife test were removed (Baldwin, 2009; Gils et al., 2012). Statistically important in projecting Aloe vera species presence data, biologically important for the establishment and of $A$. vera species, and do not display collinearity with other bioclimatic variables were selected. Variance Inflation Factors (VIF) was used to detect collinearity among the bioclimatic, to minimize the effect of multicollinearity and model overfitting (Wang et al. 2010) we excluded all variables with VIF values larger than 3. Accordingly, only two variables were excluded. All environmental factors have been converted to the same pixel size $(30 \mathrm{~m})$ and projection American Standard Code for Information Interchange (ASCII) raster grids format for further analysis.

Table 1. Environmental variables used for modeling the distribution of Aloe vera 


\begin{tabular}{l|l|l|l|}
\hline Code & Bioclimatic variable & Code & Bioclimatic variable \\
\hline Bio1 & Annual mean temperature & Bio12 & Annual Precipitation \\
\hline Bio2 & Mean diurnal range & Bio13 & Precipitation of Wettest Month \\
\hline Bio3 & Isorthemality & Bio14 & Precipitation of Driest Month \\
\hline Bio4 & Temperature seasonality & Bio15 & Precipitation Seasonality \\
\hline Bio5 & $\begin{array}{l}\text { Maximum temperature of the warmest } \\
\text { month }\end{array}$ & Bio16 & Precipitation of Wettest Quarter \\
\hline Bio6 & $\begin{array}{l}\text { Minimum temperature of the coldest } \\
\text { month }\end{array}$ & Bio17 & Precipitation of Driest Quarter \\
\hline Bio7 & Temperature Annual Range & Bio18 & $\begin{array}{l}\text { Precipitation of Warmest } \\
\text { Quarter }\end{array}$ \\
\hline Bio 8 & Mean Temperature of Wettest Quarter & Bio19 & Precipitation of Coldest Quarter \\
\hline Bio 9 & Mean Temperature of Driest Quarter & tmax & $\begin{array}{l}\text { Mean monthly maximum } \\
\text { temperature }\end{array}$ \\
\hline Bio10 & Mean Temperature of Warmest Quarter & tmin & $\begin{array}{l}\text { Mean monthly minimum } \\
\text { temperature }\end{array}$ \\
\hline Bio11 & Mean Temperature of Coldest Quarter & prec & Mean monthly precipitation \\
\hline
\end{tabular}

To estimate the impacts of the future climate on Aloe vera General Circulation Model (GCM) was used. We assessed changes in suitable habitat ranges in the 2050s (2041-2060) and 2070s (2061 2080) climate conditions in RCP6.0 (the intermediate scenario for GHG emissions) and RCP8.5(the highest scenario for GHG emissions) were used. The areas of suitability changes for the current and future were analyzed under two categories to identify the areas of suitable and none suitable using ArcGIS 10.8. The importance of the permutation and the contribution percentage are influential factors that measure the importance of the environmental variable.Permutation importance rather than the path is used in an individual run-up to the final results of the model and therefore is easier for assessing the significance of a particular variable (Songer et al. 2012).

\subsection{Data Analysis for Modelling A. vera species distribution}

MaxEnt version 3.3.3k was used to predict species distribution for $A$. vera species and classified as a background activity technique (presence information only) (Phillips et al., 2017). For $A$. vera, the MaxEnt models were calibrated to an area covering, Ethiopia. Most parts of the country were assumed that potentially be accessed by the species through dispersal. The study avoided using default MaxEnt settings for feature classes (FCs) and regularization multipliers (RMs) because these settings may compromise model performance (Radosavljevic and Anderson, 2014). Species occurrence data were partitioned using the jackknife method since the number of occurrence records was small $(<245)$ (Pearson et al., 2007). In Jackknife partitioning, species occurrence records are partitioned such that the number of bins is equal to the number of occurrences (Muscarella et al., 2014). ENMeval model performance was evaluated using AIC criteria where the model with the lowest delta AICc was considered optimal (Warren and Seifert, 2011). Nevertheless, model settings and various combinations of data partitioning do not guarantee the reliability of models projected across space and time (Muscarella et al., 2014). Hence for species, the study selected the top-three best ENMeval models and compared their 
transferability by plotting their projected suitability outputs and assessing the outputs visually based on knowledge of the species.

Species response curves were formed to examine the association between species habitat suitability and environmental variable. The prospective species distribution chart generated had values ranging from 0 to 1. These values have been grouped into four groups: high potential $(>0.6)$, good potential $(0.4-0.6)$, moderate potential (0.2-0.4), and low potential (<0.2) (Yang et al. 2013). The logistic output which generates a continuous map with an estimated probability of presence between 0 and 1 was used for model calculations. Ten cross-validation replicates were run for Aloe vera species and averaged into a single model. Predictive performance was then assessed based on the ability of each model to predict the single locality excluded from the training data set (Pearson et al., 2007). The remaining settings were left as default. Developed models were transferred across time to determine changes in suitable areas for species under different climate scenarios.

\subsection{Model performance evaluation}

The overall MaxEnt model performance was evaluated based on the threshold-independent area under the receiver operating characteristic curve (AUC) (Liu et al., 2005). AUC ranges The AUC was an efficient autonomous threshold index that can assess a model's ability to distinguish presence from absence. The ranges between 0 and 1, a value of 1 indicates perfect discrimination. The AUC $<0.5$ describes models that are less than probability and rarely occur in reality. The AUC of 0.5 is random. Model performance is classified as failing ( 0.5 to 0.6 ), bad ( 0.6 to 0.7$)$, good ( 0.7 to 0.8 ), better ( 0.8 to 0.9 ), or great ( 0.9 to 1 ) (Swets 1988). The jackknife test (systematically excluding each variable) was used to determine which variables were most important to the distribution of the species. (Yang et al. 2013). Maximum training sensitivity plus specificity logistic threshold (Liu et al., 2013) values obtained from model results were used to categorize the continuous suitability maps from MaxEnt into suitable and unsuitable areas for the species. All analyses were conducted using the USDM, raster, dismo, rgdal and rgeos package for $\mathrm{R}$ statistical software version .3.4.3 (R Core Team, 2018).

\section{Results}

\section{Distribution of Aloe vera under Changing Climate}

\subsection{Model performance and variable contributions}

The maxent models had good prediction accuracy for all the $A$. vera species the mean AUC values obtained from maxent model runs were 0.744 for $A$. vera species distribution indicating that the expected findings were good. (Fig 1).

The test of the jackknife of variable importance indicates the distributions of the A. vera species were mainly influenced by temperature variables. the most important variables which influenced species 
distribution were mean monthly maximum temperature (tmax) and Annual Precipitation (bio12) (Figure 2).

These observations were also supported by the variable's percent contributions to the maxent models which showed that the highest percentage contribution to the maxent model for Aloe vera distribution was by Mean monthly maximum temperature (tmax) followed by annual precipitation (bio12) and contributed $36.9 \%, 35.1 \%$ respectively to the MaxEnt model while mean diurnal range (bio2) and Precipitation Seasonality (bio15) contributed ( $0.7 \%$ and 1.3 respectively) very little to the distribution of Aloe vera species respectively (Table 2 ). In $\mathrm{n}$ consideration of the permutation importance, mean monthly maximum temperature (tmax)had the highest impact on the habitat model and contributed $30.2 \%$, annual precipitation (bio12) contributed 12.8\% (Table 2).

Table 1. Percent contribution of environmental variables to MaxEnt models for A.vera

\begin{tabular}{lll} 
Variables & Percent contribution & Permutation importance \\
\hline tmax & 36.9 & 30.2 \\
Bio12 & 35.1 & 12.8 \\
\hline Bio14 & 8.8 & 6.1 \\
pop & 8.5 & 8.9 \\
\hline Bio7 & 3.2 & 7.5 \\
\hline landcover & 2.3 & 4.6 \\
Bio18 & 1.7 & 5.1 \\
Bio3 & 1.4 & 9.1 \\
\hline Bio15 & 1.3 & 12 \\
Bio2 & 0.7 & 3.7 \\
\hline
\end{tabular}

\subsection{Species response to the Environmental variables}

The species response curve shows the association between environmental variables and the chance of species occurrence. Regards on the result of species response curves indicate $A$. vera prefers the Mean monthly maximum temperature ranges from 90 to $110{ }^{\circ} \mathrm{C}$, Annual Precipitation ranges from 2200 to 2400 $\mathrm{mm}$, Precipitation of Driest Month ranges from 55 to $65 \mathrm{~mm}$, Precipitation of Warmest Quarter ranges from 610 to $680 \mathrm{~mm}$, and Mean diurnal range ranges from 185 to $195 \mathrm{~mm}$ (Fig 3).

\subsection{Current distribution of $A$. vera}

The results of the Maxent models have been represented both graphically and in numeric values. Under current climate conditions, $A$. vera was projected to have favorable climatic conditions in Ethiopia covering a total of $40.45 \%$ while $59.54 \%$ is not suitable (Table 3 ). When looking at current environmental variables, Maxent produced blue color parts of the below map as suitable for the Aloe vera species distribution while the green color parts are land which is not suitable for the distribution of Aloe vera species. Aloe vera species has a geographically vast distribution in Ethiopia under the current climatic 
scenario. Its distribution is especially widespread within the central part of Ethiopia but also extends to the northern part of the country (Figure 4).

\subsection{Future projected distributions of $A$. vera species}

When looking into the future, results were developed for both 2050 and 2070 using the two different RCPs (RCP6.0 and RCP8.5). when projected to future climates Aloe vera proved to be highly sensitive to changes in climate as it lost all its suitable areas in the country. Both RCPs show a decrease in suitable habitat from the current to 2050 and again in 2070. When compared to the area Maxent determined to currently be suitable for the Aloe vera, by 2050, the suitable area under both RCP6.0 and RCP8.5 will gradually be decreasing whereas the total area of the unsuitability for Aloe vera covered around $71.37 \%$ and $72.83 \%$ under RCP6.0 and RCP8.5 respectively. Compared to the current climatic scenarios, in 2070, suitable area for the Aloe vera species is projected to cover by $25.87 \%$ and $16.86 \%$ under RCP 6.0 and RCP8.5 scenario, respectively whereas, the unsuitable area covered $74.12 \%$ and $83.15 \%$ under RCP6.0 and RCP8.5 scenario, respectively. the highest range losses were experienced in 2070 under RCP8.5 followed by 2070 RCP6.0 (Table 3). Map of future maxent model projections shows the low distribution of Aloe vera species. Mainly in Central, southern and northwestern part of the country identified as the suitable area for Aloe vera distribution in the future (Fig 5 and 6)

Table 2. The predicted size of suitability areas for Aloe vera species in Ethiopia

\begin{tabular}{|c|c|c|c|}
\hline Time & Scenarios & Suitability $\left(\mathrm{km}^{2} / \%\right.$ & \\
\hline \multirow{4}{*}{$\begin{array}{l}\text { Current } \\
2050\end{array}$} & & Suitable & Not suitable \\
\hline & & $456580.70 / 40.45$ & $672079.41 / 59.54$ \\
\hline & $\mathrm{RCl}$ & 3.62 & $805590.92 / 71.37$ \\
\hline & $\mathrm{RC}$ & 7.16 & $46 / 72.83$ \\
\hline \multirow[t]{2}{*}{2070} & $\mathrm{RCP}$ & $2 / 25.87$ & $836608.99 / 74.12$ \\
\hline & RCP8.5 & 190162.70/16.86 & $938497.41 / 83.15$ \\
\hline
\end{tabular}

\section{Discussion}

\subsection{Aloe vera habitat suitability and their environmental variables}

Climate modeling of tree distribution has shown that future global climate change will have important effects on forest ecosystems (Wang et al. 2011). Inconsistencies exist between varying climate variables models (Cheaib et al. 2012), Aloe vera is an endangered plant, and its population in its native areas has been steadily declining due to numerous human-induced threats, primarily habitat fragmentation and illegal harvesting (Oda and Anbessa, 2017). In addition, it is an economically significant species. This research showed a more detailed survey on the suitable habitat of Aloe vera in Ethiopia using the MaxEnt 
ecological niche modeling software that will help as a significant first stage in the development of strategies and policies to manage and use this important vegetation.

The models achieved AUC values of 0.74 which for models to be considered good are within the acceptable range. AUC values above 0.7 might be helpful and appropriate in evaluating the performance of a niche model (Elith.2006). MaxEnt stated that the distribution of Aloe vera was determined by precipitation and temperature factors of environmental variables hence projected future geographic ranges losses are likely due to future changes in temperature and

precipitation patterns. Accordingly, the Mean monthly maximum temperature (tmax) and Annual Precipitation (Bio12) had $72 \%$ more contribution to the distribution of Aloe vera species. Thus, changes in precipitation levels and temperatures are likely to have negative impacts on this species. The main role in determining the potential distribution habitats of Aloe vera is influenced by precipitation and temperature (khanum, 2013).

\subsection{Projection of Aloe vera species distribution under Different Climate Scenarios}

Future model projections from the 2050s and 2070s obtained from the IPCC climate change scenario indicated that climate change would significantly affect this species distribution, but the particular impacts will differ from one scenario to another. The results indicate that the Aloe vera species will experience huge geographic range losses under future climate scenarios under RCP8.5 lose the highest cover of suitable areas (83.15) was unsuitable. Reduction in Aloe vera species ranges under different climate scenarios, indicates the adverse impacts which climate change will have on this species (Table 3). Generally, the model predicted that highly and well suitable habitats would be expanded in current climatic conditions, perhaps the suitable habitats will rapidly reduce in future climatic conditions. A continuous increase in temperature had an adverse impact on plants (Xu and Xue, 2013). The areas with habitats suitable for Aloe vera distribution in the RCP8.5 scenario were lower than in RCP6.0 in both midcentury (the 2050s and 2070s).

Our study proposes that in such vulnerable environmental regions, collaborative $A$. vera habitat conservation programs and sustainable uses should be developed and implemented with grassroots support. Ethiopia is regarded as a leader in Forest conservation comprises activities to secure the longterm protection of the environmental "services" of a forest, notably its biological diversity, soil conservation, watershed regulation, and climate regulation. Precipitation and changing temperature are the main factors that influence the distribution of Aloe vera and such collaborative programs aimed at soil and water conservation will increase the habitat of Aloe vera and support Aloe vera in changing potential warming impacts. An appropriate scheme in this sense could be to implement socio-ecological frameworks for landscape planning and conservation that link human beings and their socio-culture and ecological mechanisms (Lamsaletal, 2017).

\section{Conclusion}


This study efficiently modeled Aloe vera habitat suitability for current and future climate change scenarios. In this work, we used present occurrence data to predict the potentially suitable distribution area of Aloe vera species. This research strengthened the existing body of knowledge that climate changes pose a high threat to bird species. The study has revealed that $A$. vera is under great threat of extinction due to the negative impacts of climate change. changes in climate like precipitation and temperature are likely to have a profound effect on the distribution of Aloe vera species. Hence conservation measures may need to be varied under some circumstances as one conservation strategy may not suit all species. However, conservation measures that ensure increased protection and generally reduced rate of habitat loss may suit a wide range of species. To accurately simulate changes in the suitable distribution area of a species under future climate change scenarios, responses to the influencing factors need to be fully considered in future research. It is also important that future niche models are used to comprehensively investigate the impact of human activities on species niches.

\section{References}

Araújo, M.B., Alagador, D., Cabeza, M., Nogués-Bravo, D. and Thuiller, W., 2011. Climate change threatens European conservation areas. Ecology letters, 14(5), pp.484-492.

Araújo, M.B., Pearson, R.G., Thuiller, W. and Erhard, M., 2005. Validation of species-climate impact models under climate change. Global change biology, 11(9), pp.1504-1513.

Baldwin, R.A., 2009. Use of maximum entropy modeling in wildlife research. Entropy, 11(4), pp.854-866.

Beale, C.M. and Lennon, J.J., 2012. Incorporating uncertainty in predictive species distribution modeling. Philosophical Transactions of the Royal Society B: Biological Sciences, 367(1586), pp.247-258.

Brook, B.W., Sodhi, N.S., and Bradshaw, C.J., 2008. Synergies among extinction drivers under global change. Trends in ecology \& evolution, 23(8), pp.453-460.

Cheaib, A., Badeau, V., Boe, J., Chuine, I., Delire, C., Dufrêne, E., François, C., Gritti, E.S., Legay, M., Pagé, C. and Thuiller, W., 2012. Climate change impacts on tree ranges: model intercomparison facilitates understanding and quantification of uncertainty. Ecology letters, 15(6), pp.533-544.

CSA, 2016. Compendium of Environment Statistics, CSA. Addis Ababa, Ethiopia.

Early, R., Anderson, B., and Thomas, C.D., 2008. Using habitat distribution models to evaluate large-scale landscape priorities for spatially dynamic species. Journal of Applied Ecology, 45(1), pp.228-238.

Elith, J. and Leathwick, J.R., 2009. Species distribution models: ecological explanation and prediction across space and time. Annual review of ecology, evolution, and systematics, 40, pp.677-697.

Engler, R., Guisan, A. and Rechsteiner, L., 2004. An improved approach for predicting the distribution of rare and endangered species from occurrence and pseudo-absence data. Journal of applied ecology, 
41(2), pp.263-274.

Eshun, K. and He, Q., 2004. Aloe vera: a valuable ingredient for the food, pharmaceutical, and cosmetic industries-a review. Critical reviews in food science and nutrition, 44(2), pp.91-96.

Estes, L.D., Bradley, B.A., Beukes, H., Hole, D.G., Lau, M., Oppenheimer, M.G., Schulze, R., Tadross, M.A. and Turner, W.R., 2013. Comparing mechanistic and empirical model projections of crop suitability and productivity: implications for ecological forecasting. Global Ecology and Biogeography, 22(8), pp.10071018.

Gils, H. Van, Conti, F., Ciaschetti, G. and Westinga, E. 2012. Fine resolution distribution modeling of endemics in Majella National Park, Central Italy. Plant Biosystems, 146: 276-287. https://doi.org/10.1080/11263504.2012.685194

Guisan, A. and Zimmermann, N.E., 2000. Predictive habitat distribution models in ecology. Ecological modeling, 135(2-3), pp.147-186.

Heller, N.E. and Zavaleta, E.S., 2009. Biodiversity management in the face of climate change: a review of 22 years of recommendations. Biological Conservation, 142(1), pp.14-32.

IPCC (Intergovernmental Panel on Climate Change). 2007. Climate Change 2007-The Physical Science Basis; Cambridge University Press: Cambridge, UK.

Keith, D.A., Akçakaya, H.R., Thuiller, W., Midgley, G.F., Pearson, R.G., Phillips, S.J., Regan, H.M., Araújo, M.B. and Rebelo, T.G., 2008. Predicting extinction risks under climate change: coupling stochastic population models with dynamic bioclimatic habitat models. Biology Letters, 4(5), pp.560-563.

Khanum, R., Mumtaz, A.S. and Kumar, S., 2013. Predicting impacts of climate change on medicinal asclepiads of Pakistan using Maxent modeling. Acta Oecologica, 49, pp.23-31.

Klanderud, K. and Birks, H.J.B., 2003. Recent increases in species richness and shifts in altitudinal distributions of Norwegian mountain plants. The Holocene, 13(1), pp.1-6.

Kriticos, D.J., Le Maitre, D.C. and Webber, B.L., 2013. Essential elements of discourse for advancing the modelling of species' current and potential distributions. Journal of Biogeography, 40(3), pp.608-611.

Lamsal, P., Kumar, L., Atreya, K. and Pant, K.P., 2017. Vulnerability and impacts of climate change on forest and freshwater wetland ecosystems in Nepal: A review. Ambio, 46(8), pp.915-930.

Lawler, J.J., White, D., Neilson, R.P. and Blaustein, A.R., 2006. Predicting climate-induced range shifts: model differences and model reliability. Global Change Biology, 12(8), pp.1568-1584.

Leadley, P., Pereira, H.M., Proença, V., Alkemade, R., Scharlemann, J.P., Fernandez-Manjarrés,J.F., Araújo, M.B., Balvanera, P., Biggs, R., Cheung, W.W. and Chini, L., 2010.Scenarios for global biodiversity in the 21st 
century. Science, 330(6010):1496-1501.

Leathwood*, C., 2005. 'Treat me as a human being-don't look at me as a woman': femininities and professional identities in further education. Gender and Education, 17(4), pp.387-409.

Liu, C., Berry, P.M., Dawson, T.P. and Pearson, R.G., 2005. Selecting thresholds of occurrence in the prediction of species distributions. Ecography, 28(3), pp.385-393.

Mantyka-pringle, C.S., Martin, T.G. and Rhodes, J.R., 2012. Interactions between climate and habitat loss effects on biodiversity: a systematic review and meta-analysis. Global Change Biology, 18(4), pp.12391252.

Meynecke, J.O., 2004. Effects of global climate change on geographic distributions of vertebrates in North Queensland. Ecological Modelling, 174(4), pp.347-357.

Muscarella, R., Galante, P.J., Soley-Guardia, M., Boria, R.A., Kass, J.M., Uriarte, M. and Anderson, R.P., 2014. ENM eval: An R package for conducting spatially independent evaluations and estimating optimal model complexity for Maxent ecological niche models. Methods in ecology and evolution, 5(11), pp.1198-1205.

Oda, B. K., \& AnbessaErena, B. (2017). Aloes of Ethiopia: A Review on Uses and Importance of Aloes in Ethiopia. International Journal of Plant Biology and Research, 5(1), 1-6.

Pearson, R.G., Raxworthy, C.J., Nakamura, M. and Townsend Peterson, A., 2007. Predicting species distributions from small numbers of occurrence records: a test case using cryptic geckos in Madagascar. Journal of biogeography, 34(1), pp.102-117.

Pereira, H.M., Leadley, P.W., Proença, V., Alkemade, R., Scharlemann, J.P., Fernandez-Manjarrés, J.F., Araújo, M.B., Balvanera, P., Biggs, R., Cheung, W.W. and Chini, L., 2010. Scenarios for global biodiversity in the 21 st century. Science, 330(6010), pp.1496-1501.

Phillips, S.B., Aneja, V.P., Kang, D. and Arya, S.P., 2006. Modelling and analysis of the atmospheric nitrogen deposition in North Carolina. International journal of global environmental issues, 6(2-3), pp.231-252.

Phillips, S.J. and Dudík, M., 2008. Modeling of species distributions with Maxent: new extensions and a comprehensive evaluation. Ecography, 31(2), pp.161-175.

Phillips, S.J., Anderson, R.P., Dudík, M., Schapire, R.E. and Blair, M.E., 2017. Opening the black box: An open-source release of Maxent. Ecography, 40(7), pp.887-893.

Polce, C., Termansen, M., Aguirre-Gutiérrez, J., Boatman, N.D., Budge, G.E., Crowe, A., Garratt, M.P., Pietravalle, S., Potts, S.G., Ramirez, J.A. and Somerwill, K.E., 2013. Species distribution models for crop pollination: a modelling framework applied to Great Britain. PloS one, 8(10), p.e76308. 
Porfirio, L.L., Harris, R.M., Lefroy, E.C., Hugh, S., Gould, S.F., Lee, G., Bindoff, N.L. and Mackey, B., 2014. Improving the use of species distribution models in conservation planning and management under climate change. PLoS One, 9(11), p.e113749.

Qiao, H., Soberon, J. and Peterson, A.T., 2015. No silver bullets in correlative ecological niche modelling: insights from testing among many potential algorithms for niche estimation. Methods in Ecology and Evolution, 6(10), pp.1126-1136.

Radosavljevic, A. and Anderson, R.P., 2014. Making better Maxent models of species distributions: complexity, overfitting and evaluation. Journal of biogeography, 41(4), pp.629-643.

Sahu, P.K., Giri, D.D., Singh, R., Pandey, P., Gupta, S., Shrivastava, A.K., Kumar, A. and Pandey, K.D., 2013. Therapeutic and medicinal uses of Aloe vera: a review. Pharmacology \& Pharmacy, 4(08), p.599.

Sheppard, C.S., 2013. How does selection of climate variables affect predictions of species distributions? A case study of three new weeds in N ew Z ealand. Weed Research, 53(4), pp.259-268.

Songer, M., Delion, M., Biggs, A. and Huang, Q., 2012. Modeling impacts of climate change on giant panda habitat. International Journal of Ecology, 2012.

Swets, J.A., 1988. Measuring the accuracy of diagnostic systems. Science, 240(4857), pp.1285-1293.

Thomas, C.D., Cameron, A., Green, R.E., Bakkenes, M., Beaumont, L.J., Collingham, Y.C., Erasmus, B.F., De Siqueira, M.F., Grainger, A., Hannah, L. and Hughes, L., 2004. Extinction risk from climate change. Nature, 427(6970), pp.145-148.

Walther, G.R., Post, E., Convey, P., Menzel, A., Parmesan, C., Beebee, T.J., Fromentin, J.M., Hoegh-Guldberg, O. and Bairlein, F., 2002. Ecological responses to recent climate change. Nature, 416(6879), pp.389-395.

Wang, Y., Bao, Y., Yu, M., Xu, G. and Ding, P., 2010. BIODIVERSITY RESEARCH: Nestedness for different reasons: the distributions of birds, lizards and small mammals on islands of an inundated lake. Diversity and distributions, 16(5), pp.862-873.

Warren, D.L. and Seifert, S.N., 2011. Ecological niche modeling in Maxent: the importance of model complexity and the performance of model selection criteria. Ecological applications, 21(2), pp.335-342.

Warren, D.L., Wright, A.N., Seifert, S.N. and Shaffer, H.B., 2014. Incorporating model complexity and spatial sampling bias into ecological niche models of climate change risks faced by $90 \mathrm{C}$ alifornia vertebrate species of concern. Diversity and distributions, 20(3), pp.334-343.

Xu, M.H. and Xue, X., 2013. Analysis on the effects of climate warming on growth and phenology of alpine plants. J Arid Land Resour Environ, 27, pp.137-141. 
Yang, X.Q., Kushwaha, S.P.S., Saran, S., Xu, J. and Roy, P.S., 2013. Maxent modeling for predicting the potential distribution of medicinal plant, Justicia adhatoda L. in Lesser Himalayan foothills. Ecological engineering, 51, pp.83-87.

\section{Figures}

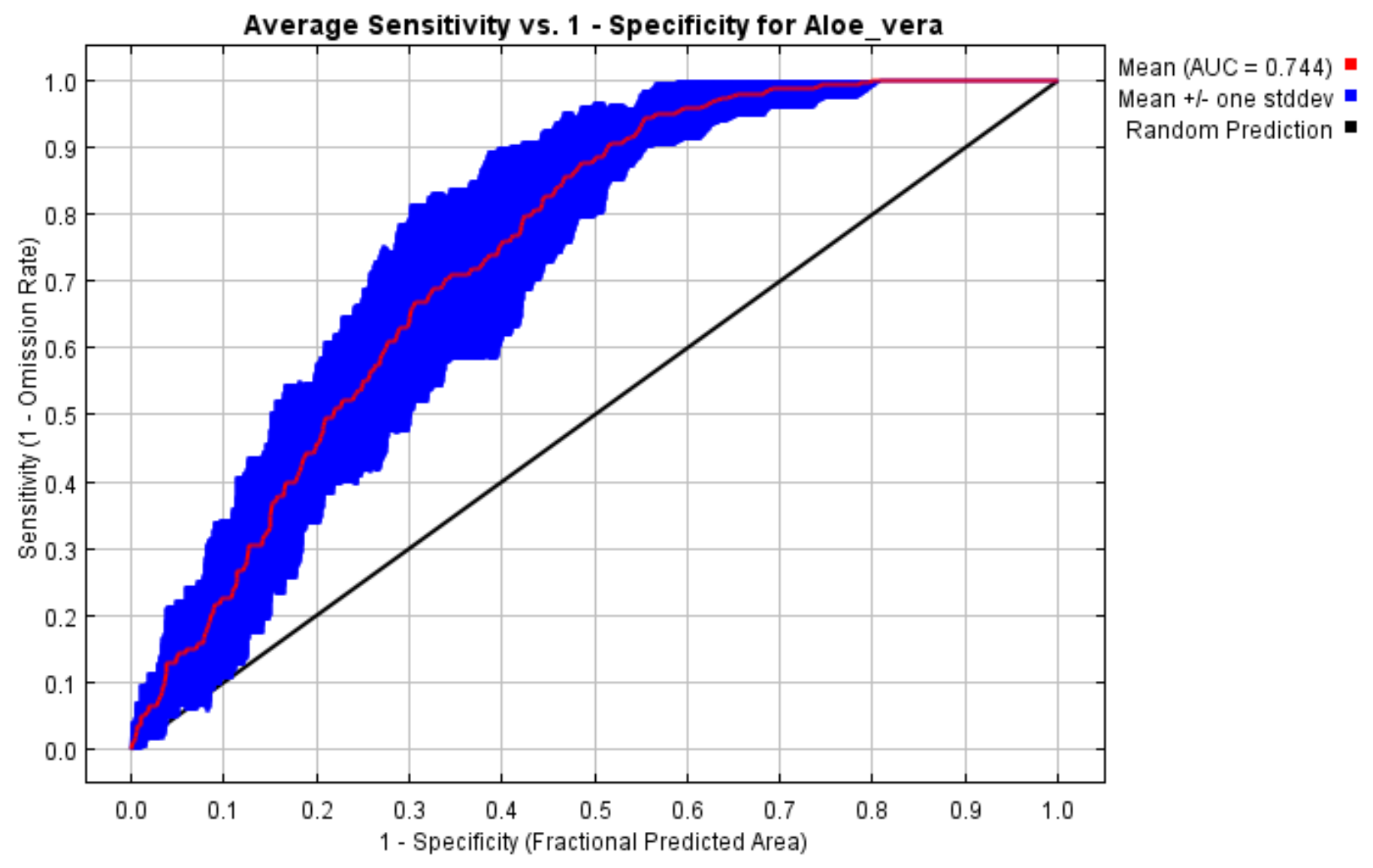

Figure 1

ROC curve and AUC value of $A$. vera distribution in Ethiopia 


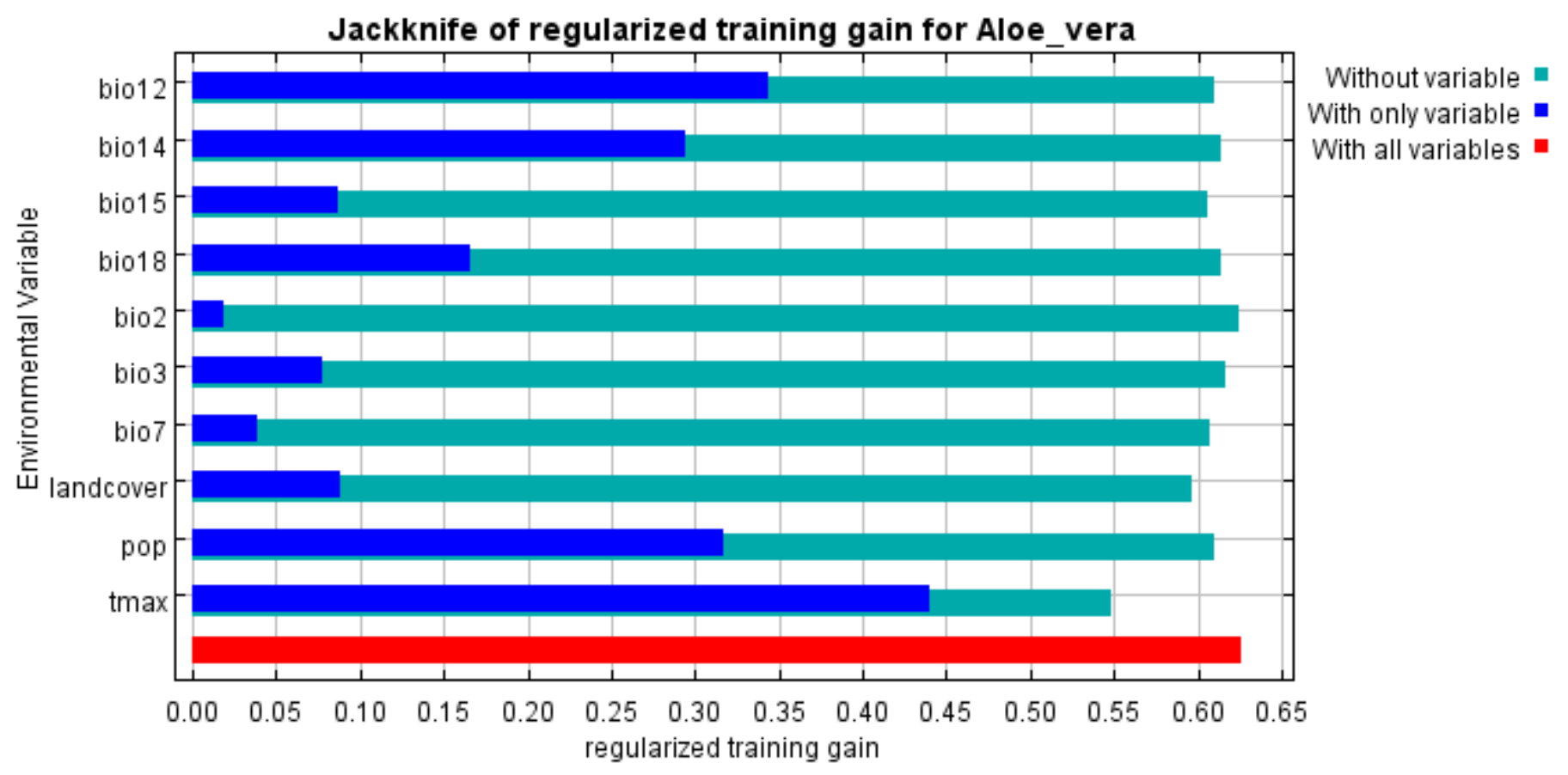

Figure 2

predictive power of different environmental variables based on the jackknife of regularized training gain 

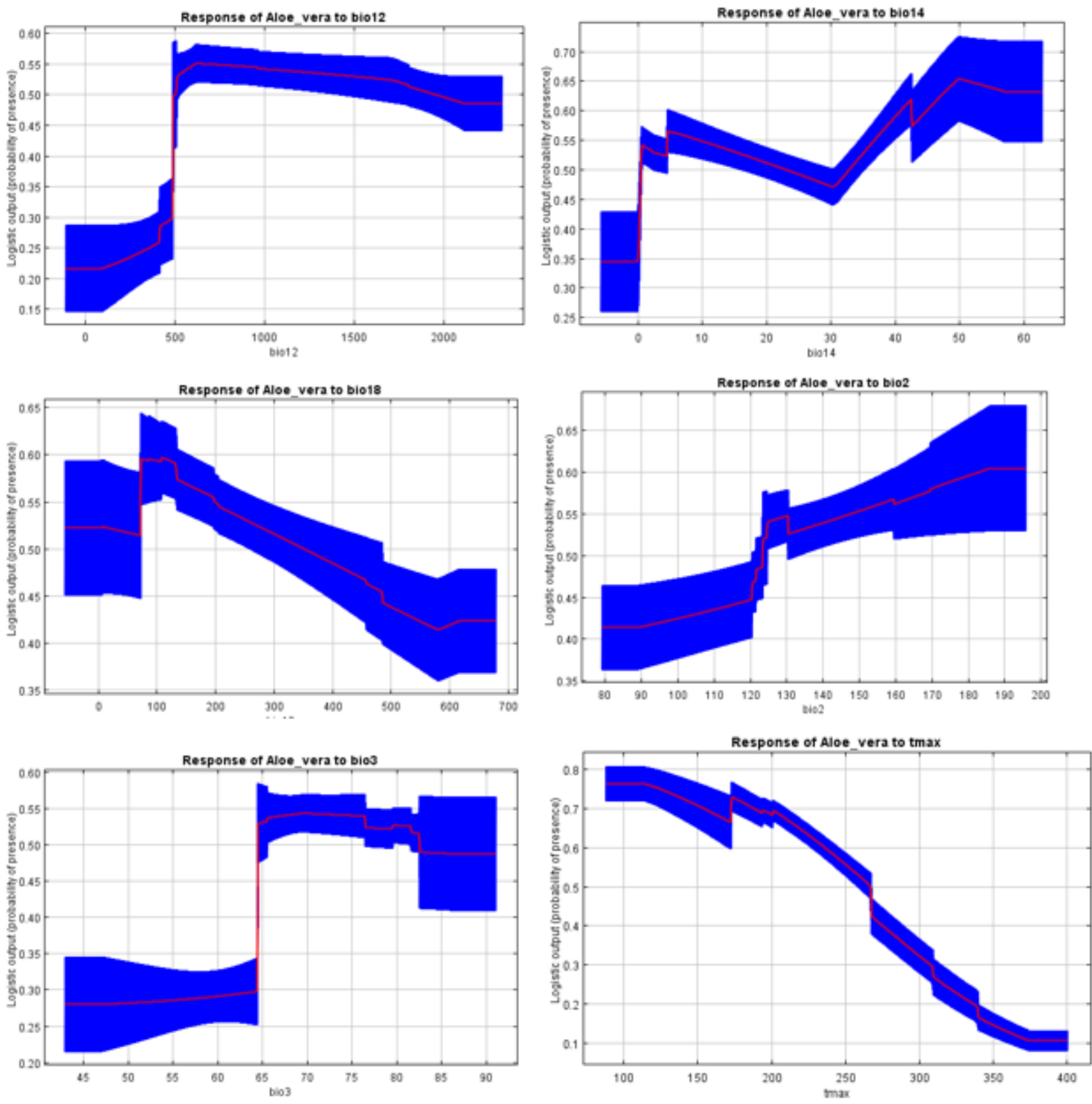

Figure 3

Response curves for A. vera species distribution in Ethiopia 


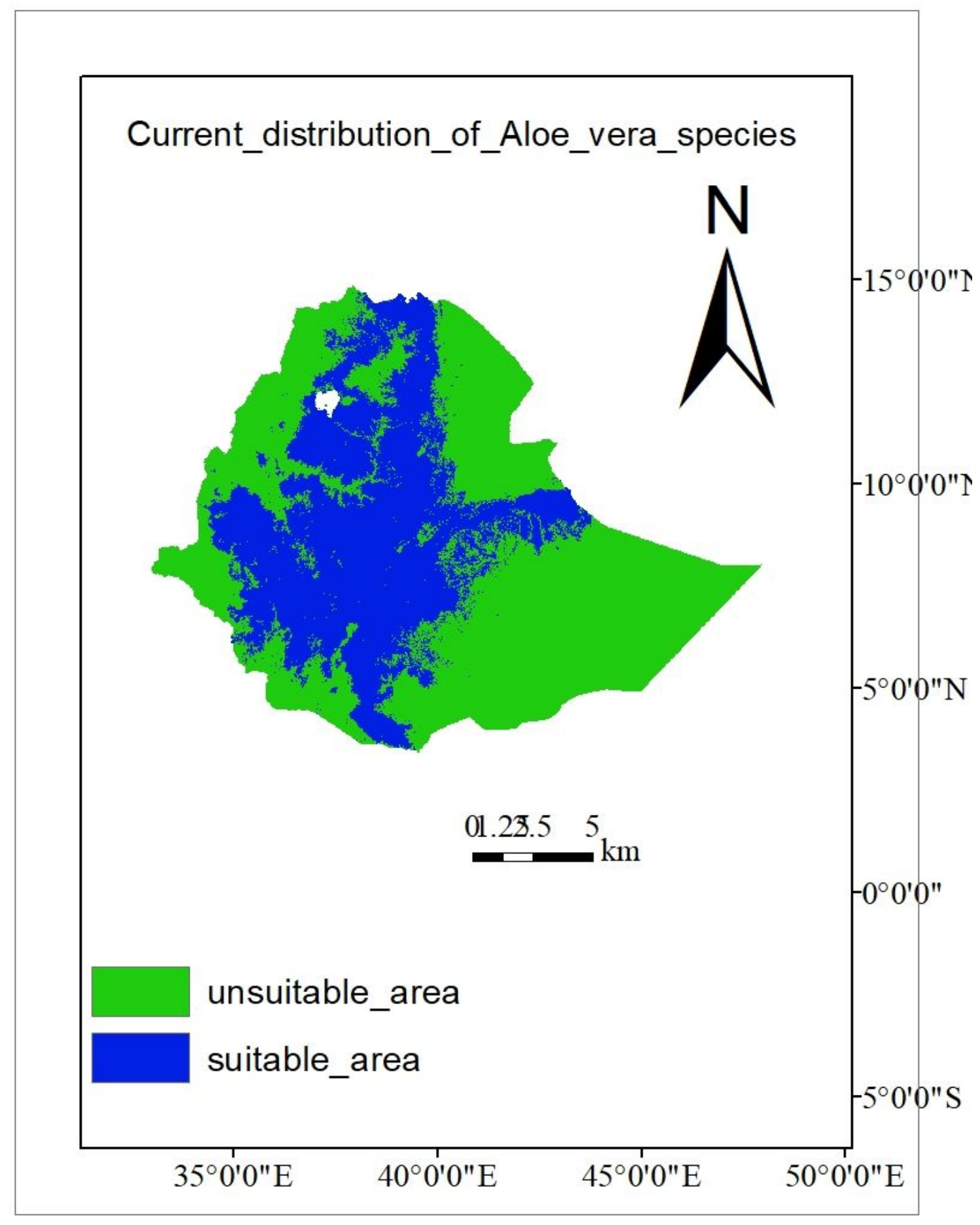

Figure 4

Potentially suitable climatic distribution of A. vera under a current climate scenario in Ethiopia 

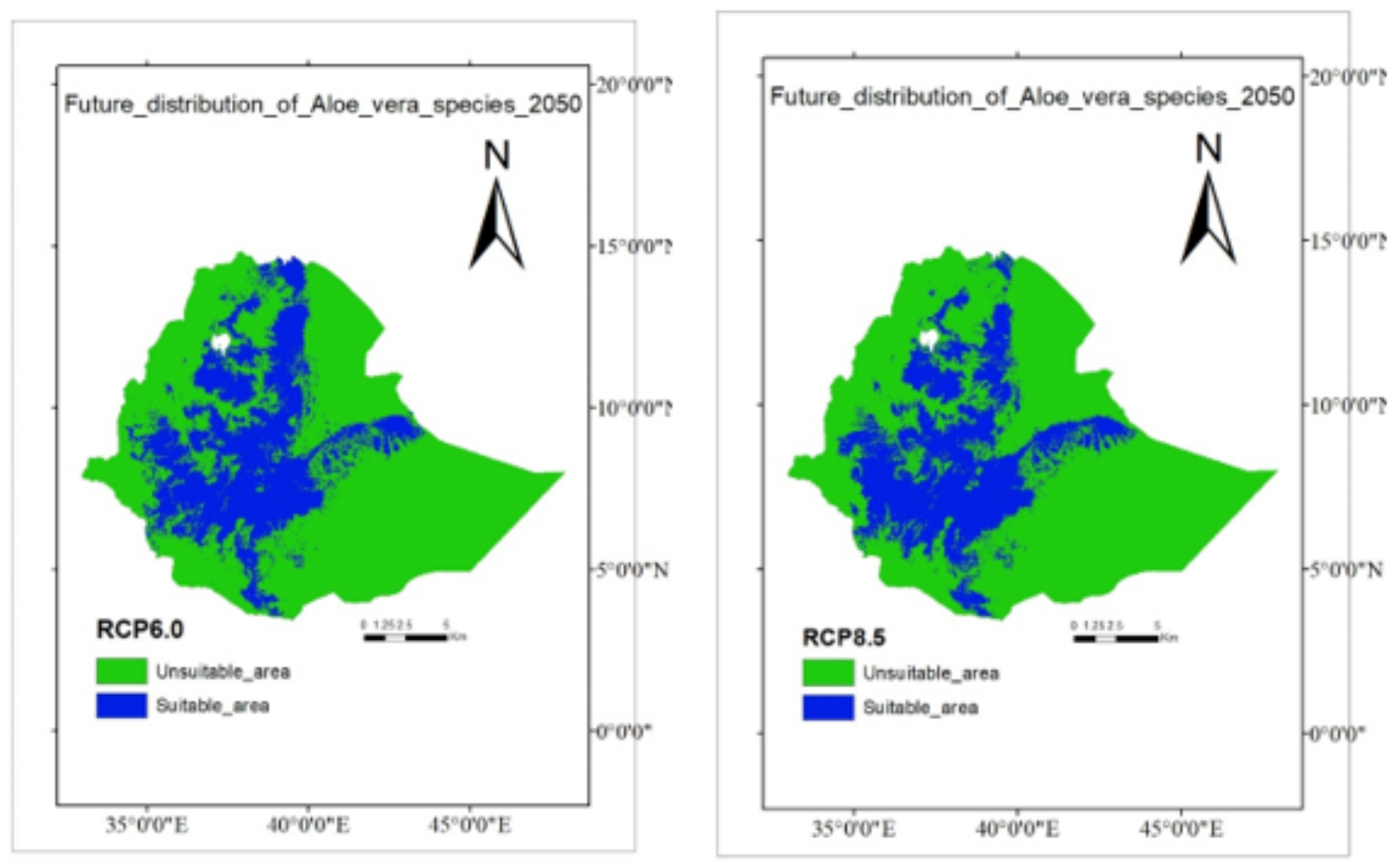

Figure 5

Suitable habitat for Aloe vera in 2050s RCP6.0, RCP8.5
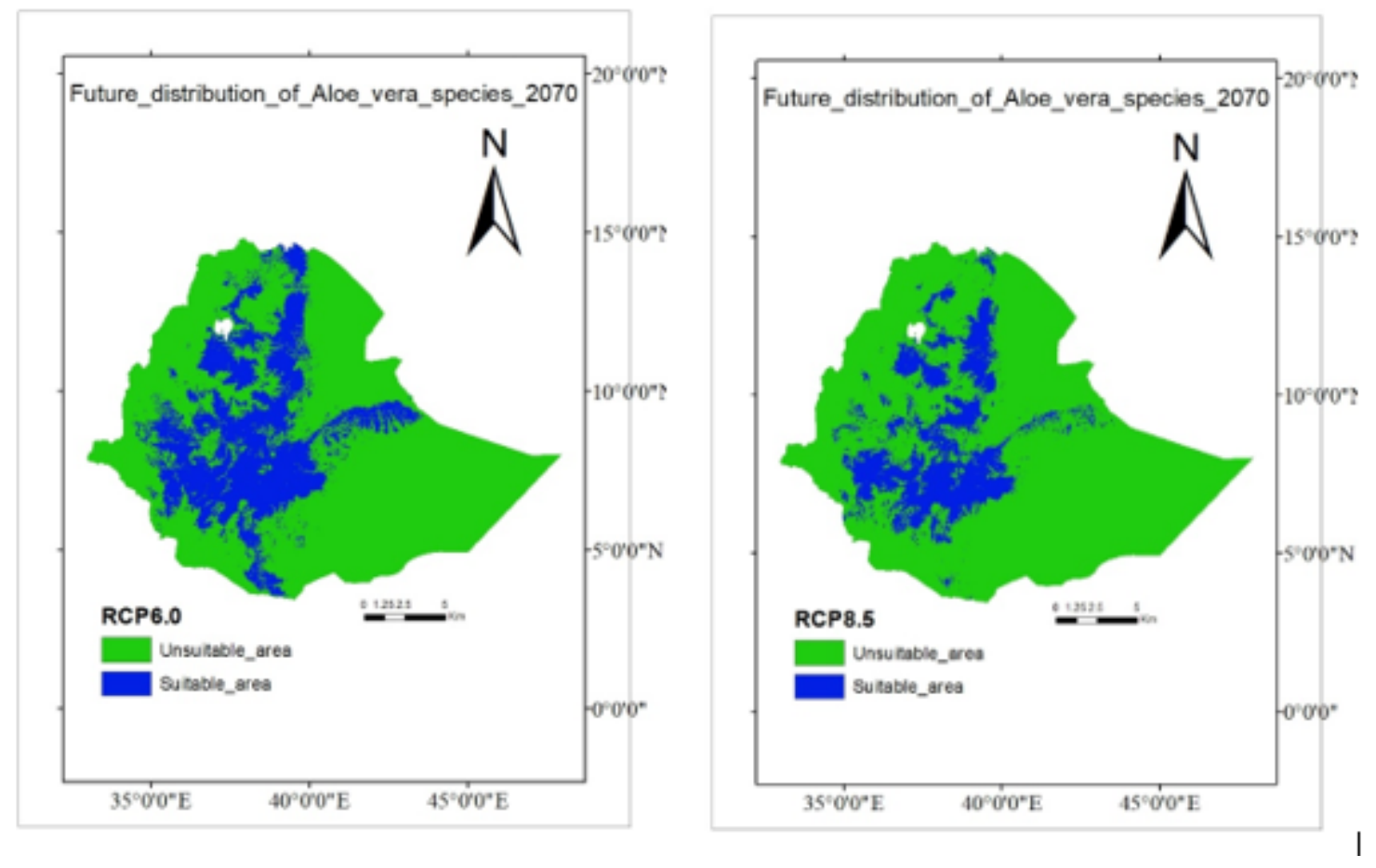

Figure 6

Suitable habitat for Aloe vera in 2070s RCP6.0, RCP8.5 